\title{
A NEW OMOPHRON AND A NEW SIAGONA FROM THE PHILIPPINES (COLEOPTERA: CARABIDAE)**
}

\author{
By P. J. Darlington, Jr. \\ Museum of Comparative Zoology
}

The following two new species from the Philippines constitute zoogeographically important range extensions of the carabid genera Omophron and Siagona. They are described now so that I can refer to them in discussion of the distribution of Carabidae in the IndoAustralian Archipelago in Part IV of my "Carabid Beetles of New Guinea."

\section{Tribe OMOPHRONINI \\ Genus Omophron Latreille}

Omophron is usually considered to be the only genus of its tribe. The insects are broadly oval, multistriate, often complexly marked carabids which inhabit sandy shores of rivers and lakes. They are usually nocturnal and stay hidden in closed burrows in the sand by day, but they may be routed out by water thrown over the sand in which they are hiding.

Distribution of the genus. Africa and Madagascar, Europe and Asia to Japan, and North and northern Central America; but not South America and not the Australian Region. An old record for New Caledonia is considered an error (Banninger 1918, p. I09). In the Oriental Region, species are numerous from India to northern Indo-China, and a few occur south through the Indo-Chinese Peninsula, but none is known from the Malay Peninsula and, until now, none has been found in the Indo-Australian Archipelago or the Philippines, so the present new species from Luzon considerably extends the known range of the genus.

Omophron luzonicus sp. nov. (Figs. I, 2)

Types. Holotype $0^{\top}$ (Museum of Comparative Zoology, Type No. 27,93I) and 20 paratypes all from Central Plains of Luzon, Philippine Islands, Feb. - Sept. 1945, collected by myself. The entire type series was taken from sandy river banks and bars, chiefly along the Rio Pampanga.

Description. Form and pattern as figured; back of head and discal areas of pronotum and elytra blackish green, with marginal pattern

\footnotetext{
*Published with the aid of a grant from the Museum of Comparative Zoology.

Manuscript received by the editor October 26, 1967
} 

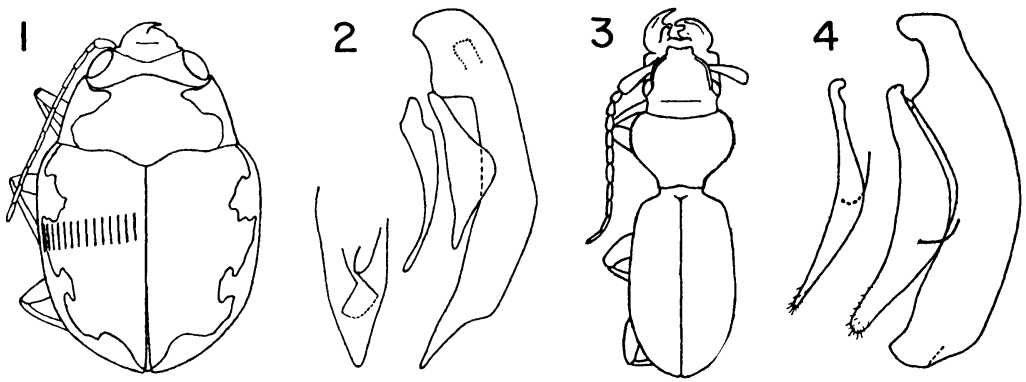

Figures 1 and 2. Omophron luzonicus, n.sp. Figures 3 and 4. Siagona sinistra n.sp.

whitish testaceous; below testaceous with a broad median brown area from prosternum to 2nd ventral segment; appendages whitish testaceous; most of upper surface including elytral intervals with lightly impressed but distinct isodiametric microsculpture. Head: mandibles with upper edge of scrobe only moderately raised; antennae with segment I with I seta, segments 3 and 4 with usual subapical setae but without extra setae on outer margins; clypeus bisetose, slightly or indistinctly margined, with suture rounded or subangulate; surface of head at sides and posteriorly moderately punctate, front nearly impunctate; subocular ridges present, space between ridge and eye rugose-punctate. Prothorax with pronotal disk slightly depressed basally, rather finely and sparsely punctate, a little more closely so anteriorly; lateral marginal channels rather narrow, not punctate; median line lightly impressed, slightly abbreviated at both ends. Elytra convex as usual; each with I 5 moderately impressed, lightly punctate striae; striation almost entire except striae $2-3$ and $7-8$ ending about $\mathrm{I} / 3$ from apex (varying in exact length and connections); stria I I reaching to or within apical I/4; intervals moderately convex, impunctate, but with microsculpture as described. Below: sterna and first 2 ventral segments with scattered punctures of moderate size; epipleurae not punctate; suture between prosternal and proepisternal processes (behind anterior coxae) usually not impressed; middle coxa with I seta, on inner side. Male with 2 basal segments each front tarsus and first segment middle tarsus slightly dilated, with sexual pubescence below; copulatory organs as figured (Fig. 2). Length $6.0-6.5 \mathrm{~mm}$.

Remarks. I am unable to say from which Asiatic stock this species is derived, for its characters are mixed. In Banninger's (I9I8) 
grouping of the species of Omophron, it falls in the first half of couplet II, with axillaris Chaudoir and certain African species. In Andrewes' (1929, pp. I4I-143) key to the Omophron of India, Burma, etc. it falls between axillaris and rotundatus Chaudoir, but differs from both in possessing distinct subocular ridges. It differs further from axillaris in having a longer it th elytral stria, less coarsely punctate head and pronotum, and more obvious microsculpture on elytral intervals, and from rotundatus in greater extent of the dark color pattern and in finer punctation of head and pronotum. The wide extent of the dark color and the fineness of the punctation distinguish it also from saigonensis Chaudoir. It is superficially similar to stictus Andrewes (1933) of Tonkin, but stictus has a strongly margined clypeus and is relatively coarsely punctate above. The Museum of Comparative Zoology possesses, and I have examined, specimens of all of these species except saigonensis, which I know only from descriptions.

\section{Tribe SIAGONINI}

\section{Genus Siagona Latreille}

This is the principal or only genus of its tribe - whether Luperca of Africa and India and Enceladus of South America should be included in the same tribe is still an open question. The species of Siagona are characteristically shaped, flattened insects which are said to live sometimes under stones, sometimes under bark or between leaf-sheaths of plants.

Distribution of the genus. Africa and Madagascar, southern Europe, Asia Minor etc., and the Oriental Region. In the latter, species are numerous from India to Indo-China, and at least two occur southward into the Malay Peninsula, but only one, insulana Andrewes ( 1936) of Java, has been recorded from the islands east of Asia. The present new species from Mindoro considerably extends the known range of the genus.

\section{Siagona sinistra sp. nov. (Figs. 3, 4)}

Types. Holotype $0^{x}$ (California Academy of Sciences) and 2 paratypes ( $\sigma^{*}$ in Museum of Comparative Zoology, Type No. 3I,603; + in California Academy of Sciences) all from San José, Mindoro, Philippine Islands, Oct. I945 (E. S. Ross). The specimens were "found in rotting bark of living Buri palm (ESR)."

Description. Form as figured; black, appendages piceous; above rather shining, unevenly and rather sparsely punctate and pubescent, mostly without distinct microsculpture; labrum, sides of neck, im- 
pressions of pronotum, margins and apices of elytra, and much of lower surface with more or less distinct, close, nearly isodiametric microsculpture. Head large; clypeal suture impressed; lateral ridges rather thick, becoming obsolete posteriorly above or just back of posterior edges of eyes, rounded anteriorly, not distinctly interrupted at the bend but obliquely grooved externally; neck constriction im. pressed; surface of head unevenly punctate, almost impunctate on middle of front and behind neck constriction; antennae with first segment moderately, not suddenly clavate; supra-maxillary plates dilated laterally, angulately rounded; mandibles of both sexes expanded and margined externally near base, those of male broadly, irregularly impressed and wrinkled above near base, the left one with a strong tubercle on inner side of upper surface. Prothorax: pronotum with fine median line and deeper, uninterrupted lateral sulci; surface of pronotum punctate across base and apex and near lateral margins, and much more sparsely so on disk. Elytra each with a distinct, short plica above the humerus, directed backward and outward; elytral surface rather finely punctate, the punctures sparse on the disk. Inner wings fully developed. Stridulating files, under lateral margins of prothorax, present in both sexes. Male with mandibles modified as described above; copulatory organs as figured (Fig. 4). Length : I9- $19.5 \mathrm{~mm}$.

Remarks. Twenty-seven previously described species of Siagona are recognized from the Oriental Region. Most of them are included in Andrewes' ( I929, pp. I78-I8I), "British India" key, and I8 of them are represented in the Museum of Comparative Zoology, although not all by males. Nevertheless I have had difficulty in placing the present new species satisfactorily.

The most striking characteristic of the new species is the tubercle of the left mandible of the male. Carinae or tubercles are variously developed on the upper surface of the mandibles inwardly near the base, in males only, in different Oriental Siagona. Many of the species lack them. The males of obscuripes Chaudoir, strata Dejean, and baconi Chaudoir have a longitudinal carina about equally developed on each mandible, the carinae being respectively weak, moderate, and strong in the three species named. The male of induta Chaudoir is said to have an elevated boss on each mandible, that on the left higher than that on the right. The male of crassidens Bates is said to have only the left mandible tuberculate. The males of angulifrons Bates and rustica Andrewes are said to have the right mandible carinate, the left one only vaguely or not so. Andrewes 
(1929) describes the condition in some other species. Of previously known Oriental Siagona, only crassidens (of southern Indo-China) has the male mandible armed nearly like that of the present new species, but the latter, compared with Bates' ( I 889) description of crassidens, is larger, with head ridges more abbreviated posteriorly, with sparser elytral punctation, and with the mandibular tubercle not bilobed.

Andrewes' key (referred to above) is based chiefly on asexual characters and does little to help place the new species. The latter does not fit into the key: it is winged and large (couplets I and 2), but the lateral ridges of the head do not nearly reach the neck construction. In wings, size, and head ridges the new species is like sublaevis Chaudoir, which is known only from southern Indo-China, Siam, and the Malay Peninsula, and which is therefore omitted from the "British India" key. There are two specimens, both females, of sublaevis in the Museum of Comparative Zoology, and the female of the new species matches them in most characters including the presence of an unusually distinct, short, post-humeral plica on each elytron. The only significant difference I note is sparser punctation of the disk of the elytra in the new species. But Chaudoir (I876) described sublaevis, from Bangkok, from a good series of both sexes, and the male has no mandibular tubercle. The Javan insulana Andrewes (1936), of which I have one male, is a smaller species, without distinct post-humeral elytral plicas, but with nearly similar head ridges. It lacks mandibular tubercles.

Taking one consideration with another, I think that the new Philippine species most likely represents the stock of sublaevis, and that the mandibular tubercle of the male has been developed independently, not inherited from an Asiatic ancestor, and I suspect that insulana may prove to be a modification of the same stock rather than a relative of fabricii Andrewes as Andrewes (1936) originally supposed. It will require a revision of a number of Oriental Siagona to decide these possibilities.

\section{REFERENCES}

ANDREWES,

1929. Fauna of British India etc., Coleoptera, Carabidae I.

1933. Annals and Magazine of Natural History (10)11: 99.

1936. Annals and Magazine of Natural History (10) 17: 307-308.

BANNINGER

1918. Deutsche Ent. Zeits. for 1918: 97-109. 
BATES

1889. Ann. Soc. Ent. France (6) 9: 263.

\section{Chaudoir}

1876. Bull. Soc. Nat. Moscow 50:86. 

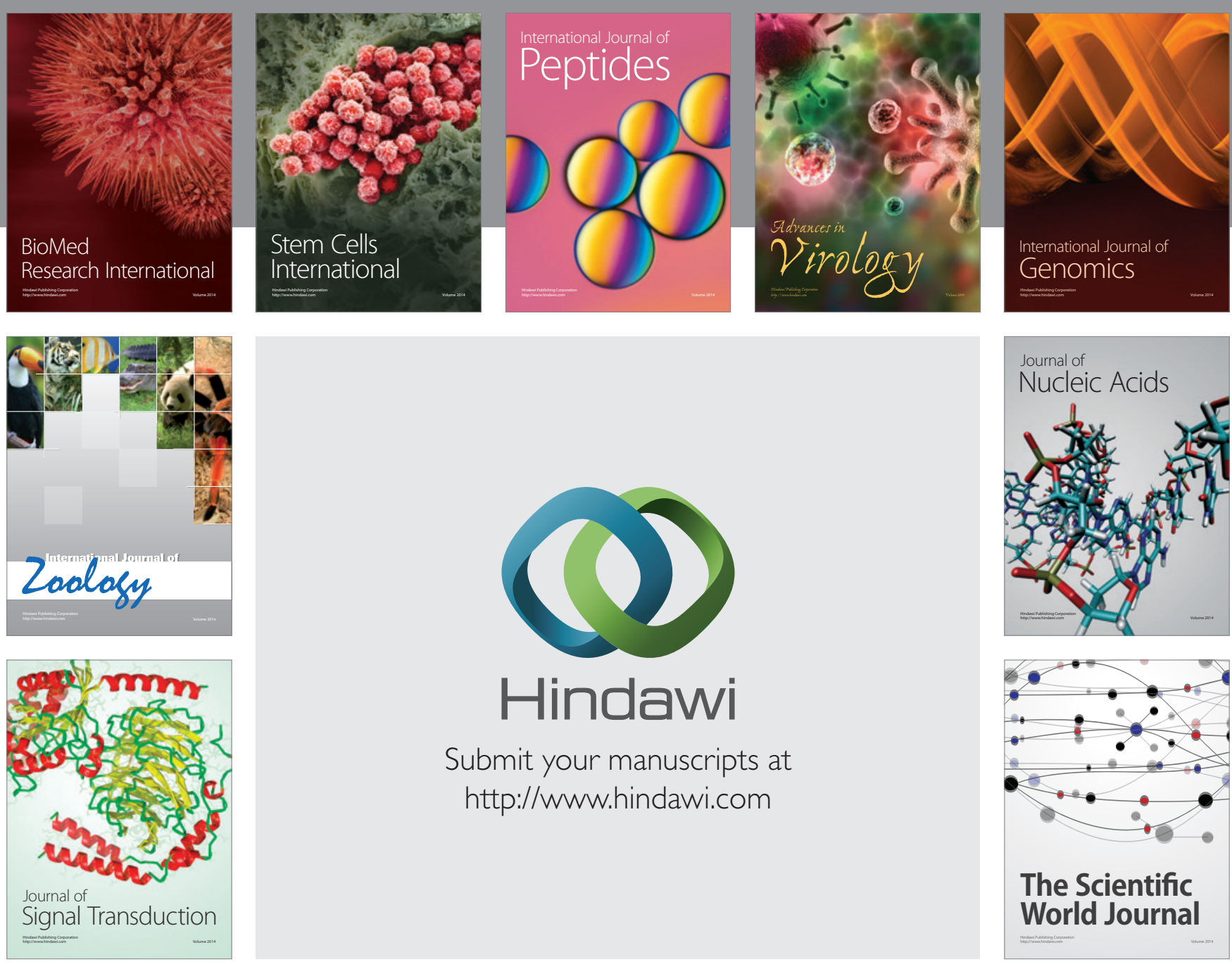

Submit your manuscripts at

http://www.hindawi.com
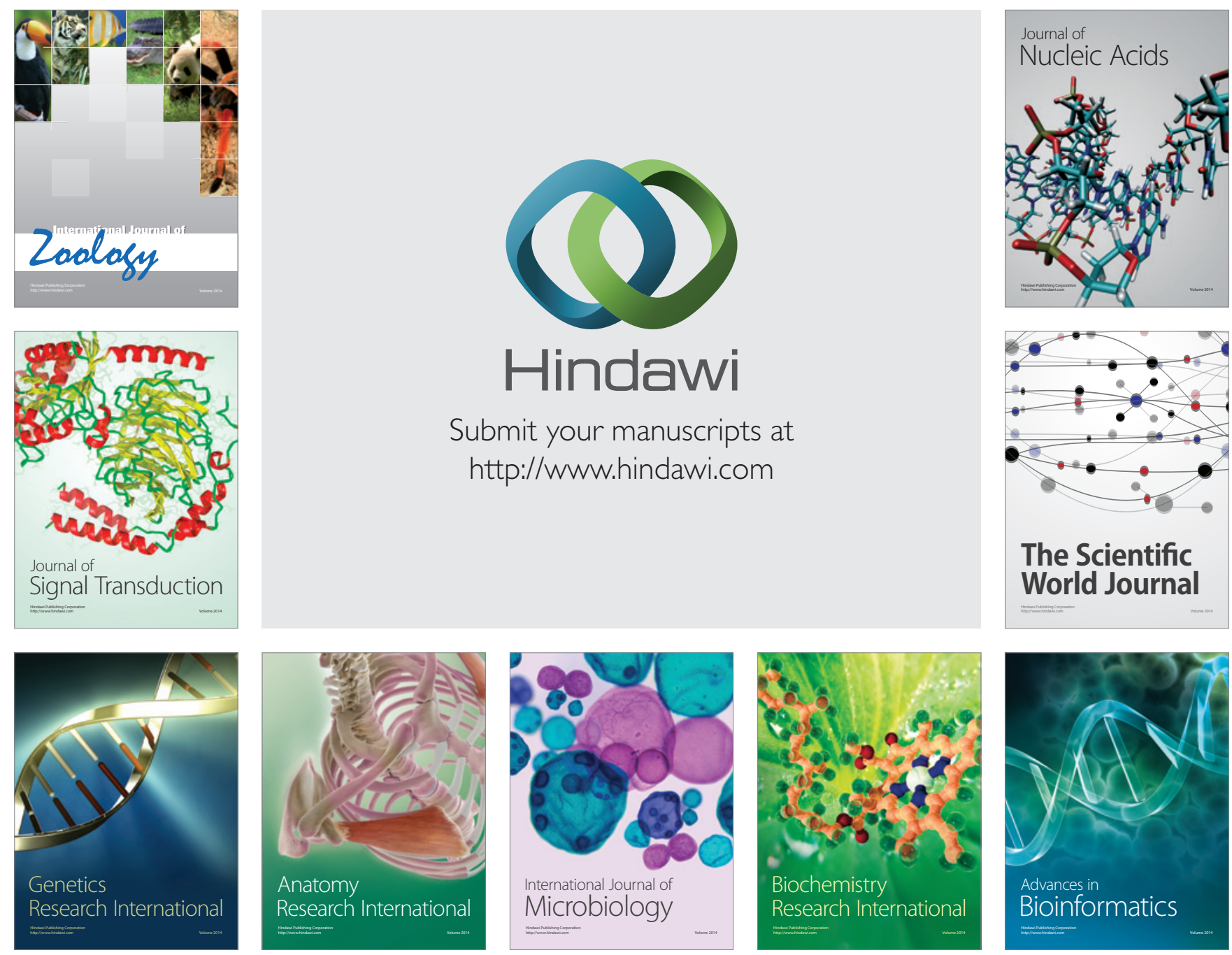

The Scientific World Journal
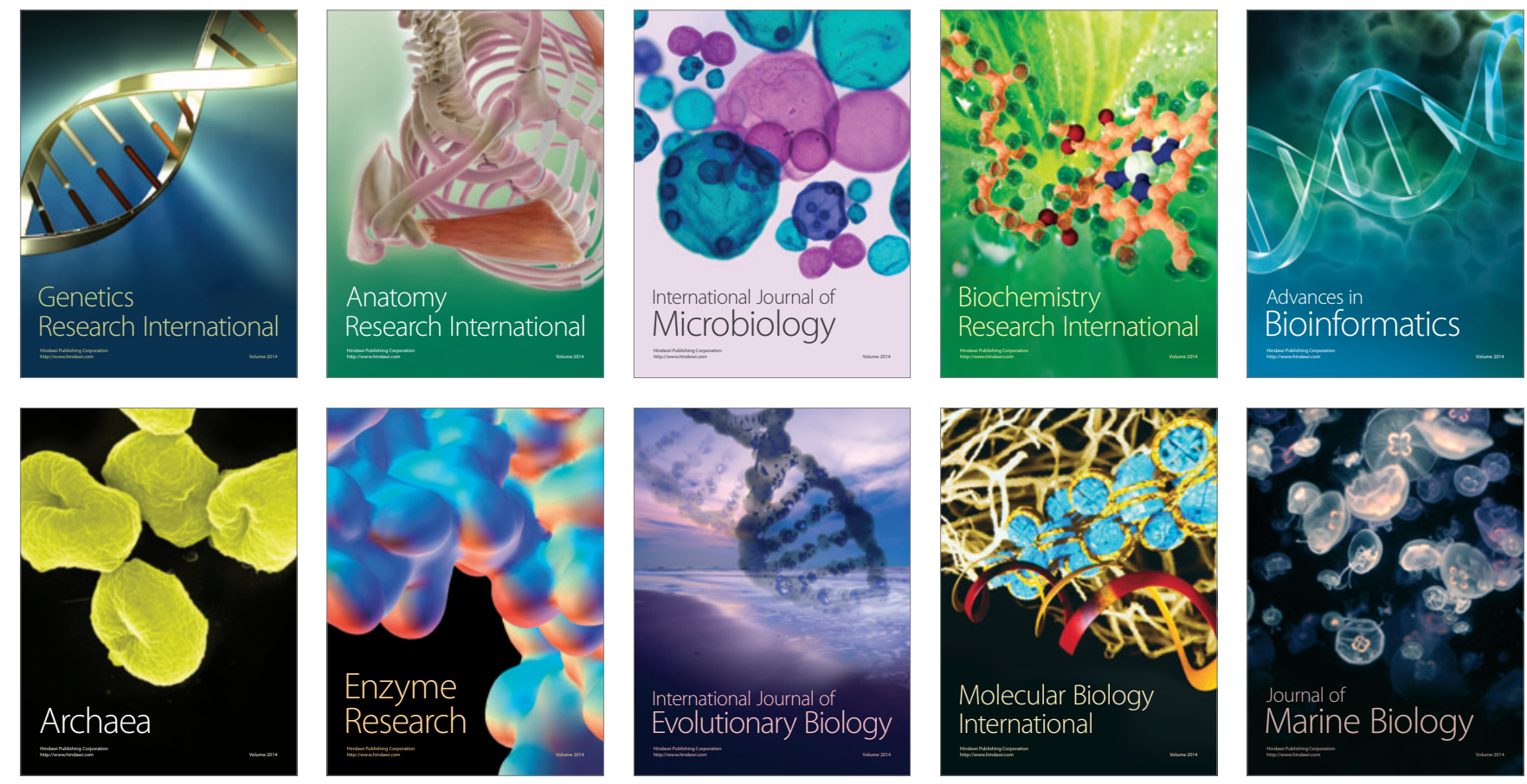